\title{
The origin of Tertiary high-alumina basalts in central Urumieh-Dokhtar magmatic arc, Iran: Constraints from geochemistry, $\mathrm{U}-\mathrm{Pb}$ geochronology and $\mathrm{Nd}-\mathrm{Hf}$ isotopes
}

\author{
SHAHROUZ BABAZADEH ${ }^{1}$ *, MASSIMO D'ANTONIO ${ }^{2}$, \\ JOHN M. COTTLE ${ }^{3}$, JALIL GHALAMGHASH ${ }^{1}$, DAVOOD \\ RAEISI ${ }^{4}$, YAJUN AN ${ }^{5}$ \\ ${ }^{1}$ Research Institute for Earth Sciences, Tehran 13185- \\ 1494, Iran; Shahrouz.babazadeh@gmail.com \\ ${ }^{2}$ Dipartimento di Scienze della Terra, dell'Ambiente e \\ delle Risorse, University Federico II of Naples, I-80126, Italy \\ ${ }^{3}$ Department of Earth Science, University of California, \\ Santa Barbara, CA 93106-9630, USA \\ ${ }^{4}$ University of Tehran, Tehran, 14155-64155, Iran \\ ${ }^{5}$ State Key Laboratory of Isotope Geochemistry, \\ Guangzhou Institute of Geochemistry, Chinese Academy of \\ Sciences, Guangzhou 510640, China
}

High-alumina basalts in the Urumieh-Dokhtar magmatic arc (UDMA) of Iran have been seldom reported to date. Tertiary volcanism in central UDMA is represented by the Eshtehard high-alumina lavas, classified as calc-alkaline basalt and basaltic andesite, and K-calc-alkaline andesites and dacites. $\mathrm{U}-\mathrm{Pb}$ dating by LA-ICP-MS of zircon yielded ages of ca. 47 , 43 and 41 Ma for basaltic, andesitic and dacitic samples, respectively. Major and trace element variations indicate a general increase in incompatible trace elements with differentiation, consistent with the effects of fractional crystallization. The uniform $\mathrm{ENd}(-0.8$ to 1.8$)$ and variation of $\mathrm{EHf}_{(\mathrm{t})}(-6.4$ to +6.5 ; av. +0.7$)$ values indicate the major source component has probably been a mantle domain. Partial melting followed by fractional crystallization under hydrous conditions, determining weak negative to positive $\mathrm{Eu}$ anomaly and negative variation between $\mathrm{Al}_{2} \mathrm{O}_{3}$ and $\mathrm{SiO}_{2}$, can justify the generation of such high-alumina basalts magmatic suite. Isotopic and trace elements modelling suggests mixture of less than $10 \%$ Cadomian upper crust and more than $90 \%$ of primitive mantle. This is in agreement with slightly concave up and typical straight-line trends of crystal size distribution (CSD) curves, which also suggest mixing between primitive mantle and up to $4 \%$ sediment melts. We hypothesize that a descending slab migrating backwards in the asthenospheric mantle (slab rollback) in the Eocene resulted in strong upwelling of the asthenosphere to a relatively shallow level. Continuous supply of hot mantlederived magmas led to interaction between moderately basic melts and the overlying crust, experiencing limited AFC processes en route to the surface. 